\title{
CORTE, PARENÉTICA E POLÍTICA: \\ O INFANTE D. PEDRO CARLOS DE BOURBON E BRAGANÇA (1786- \\ 1812)
}

\author{
Isabel Drumond Braga \\ (Universidade de Lisboa, Faculdade de Letras e CIDEHUS-UE) \\ isabeldrumondbraga@,hotmail.com
}

\section{RESUMO}

Neste texto pretende fazer-se uma aproximação à figura do infante D. Pedro Carlos de Bourbon e Bragança, tendo em especial atenção fontes como os sermões e os elogios que se publicaram imediatamente a seguir à sua morte, sem descurar, naturalmente, as notícias publicadas nas gazetas de Madrid, Lisboa e Rio de Janeiro e alguma correspondência. Por outro lado, procura fazer-se a ligação entre as repercussões da expansão napoleónica nas políticas espanhola e portuguesa e na consequente partida da Corte para o Brasil, através de um infante que viveu durante alguns anos e pereceu num espaço do império português.

PALAVRAS-CHAVE: D. Pedro Carlos de Boubon e Bragança; Brasil; Espanha; Portugal; Parenética.

\section{COURT, PARENETIC AND POLITICS: THE INFANTE D. PEDRO CARLOS DE BOURBON E BRAGANÇA}

\begin{abstract}
This papers aims to study the figure of the infante D. Pedro Carlos de Bourbon e Bragança, with sources such as the sermons and the eulogies published immediately after his death, as well as the news published in the gazettes of Madrid, Lisbon and Rio de Janeiro and some correspondence. We also intent to understand the repercussions of the Napoleonic expansion on Spanish and Portuguese politics and the consequent departure of the Court for Brazil through a prince who had a short live and perished in the Portuguese empire.
\end{abstract}

KEY-WORDS: D. Pedro Carlos de Boubon e Bragança; Brazil; Spain; Portugal; Parenetics. 
«[Os príncipes] não nasceram senão para a felicidade dos homens».

António Vieira da Soledade ${ }^{1}$

Com a presença da Corte portuguesa no Brasil (1808-1821), teve lugar, pela primeira vez na América, um conjunto de cerimónias relativas à família real. De entre estas, cabe destacar as que se ligaram à conjuntura política, como a chegada à então colónia e os aniversários dessa chegada, as derrotas militares francesas, a elevação do Brasil a reino, a aclamação de D. João VI e, especialmente, os acontecimentos familiares, tais como nascimentos, casamentos e mortes. Neste sentido, num curto espaço de dois anos (1810-1812), uma figura foi pioneira, tendo estado ligada a três momentos relevantes: o casamento, a paternidade e a morte. Trata-se de D. Pedro Carlos de Bourbon e Bragança (Aranjuez, 18 de junho de 1786 - Rio de Janeiro, 4 de julho de 1812), infante de Espanha e de Portugal.

Neste texto pretende fazer-se uma aproximação a esta figura, tendo em especial atenção fontes como os sermões e os elogios que se publicaram imediatamente a seguir à sua morte, sem descurar, naturalmente, as notícias publicadas nas gazetas de Madrid, Lisboa e Rio de Janeiro e alguma correspondência. Por outro lado, procura fazer-se a ligação entre as repercussões da expansão napoleónica nas políticas espanhola e portuguesa e na consequente partida da Corte para o Brasil, através de um infante que viveu durante alguns anos e pereceu num espaço do império português.

1. D. Pedro Carlos, cuja biografia temos em preparação, tem merecido pontuais referências aos historiadores ${ }^{2}$. Filho de D. Gabriel de Bourbon y Saxónia (1752-1788) e de D. Mariana Vitória de Bragança (1768-1788) era neto, por via paterna, dos reis de Espanha, Carlos III (1716-1788) e Maria Amália de Saxónia (1724-1760)루, e, por via materna, dos monarcas de Portugal, D. Maria I (1734-1816) e D. Pedro III (1717-1786), de quem foi o primeiro neto. Durante o segundo ano de vida perdeu a mãe, o pai, um dos dois irmãos recém-nascidos - o outro, a infanta Maria Carlota, falecera no ano anterior - e o avô paterno. O materno falecera pouco tempo antes do seu nascimento.

O infante chegou a Portugal em novembro de 1789, para ser criado na corte portuguesa, sob a tutela de sua avó, a rainha de Portugal, e de seu tio, o futuro monarca D. João VI (1769-1826). Mas as primeiras informações que acudiram a Lisboa foram

\footnotetext{
${ }_{1}$ António Vieira da Soledade, Oração Funebre que nas Exequias do Serenissimo Senhor D. Pedro Carlos de Bourbon e Bragança, Almirante General da Marinha Portugueza junto à Real pessoa, recitou na igreja de Santa Rita desta Corte, no dia 8 de julho do anno de 1812 ..., (Rio de Janeiro: Impressão Régia, 1812), 24.

${ }^{2}$ A exceção é o recente trabalho de Alice Lázaro, Andorinhas e Sabiás: os casamentos em Espanha das filhas de D. João VI (1810-1823) (Lisboa: Chiado Editora, 2018). Anteriormente, apenas se podem encontrar algumas referências ao infante em trabalhos sobre a época ou sobre diversas figuras da Casa Real.

${ }^{3}$ Sobre o reinado de Carlos III, cf., por exemplo, Antonio Domínguez Ortiz, Carlos III y la España de la Ilustración 2. ${ }^{a}$ ed. (Madrid: Alianza Editorial, 2016); Giuseppe Caridi, Carlos III: un grande rey reformador en Nápoles y España (Madrid: La Esfera de los Libros, 2015).
} 
anteriores ao seu nascimento, tendo começado com os rumores de gravidez de D. Mariana Vitória, passando por todo o período de gestação, nascimento, batizado e primeiros tempos de vida. A correspondência de D. Maria I, D. Pedro III e do infante, depois príncipe D. João (VI) com a infanta de Portugal é rica neste tipo de notícias ${ }^{4}$. A título de exemplo, assinale-se: em 7 de outubro de 1785, D. Pedro III mostrou alegria por saber que a filha estava de esperanças e logo lhe deu conselhos, designadamente que não se apertasse nem usasse espartilho e que se afastasse de assuntos que a enfadassem ${ }^{5}$. Em meados de janeiro de 1786, a rainha de Portugal congratulou-se com a notícia de a infanta já sentir a criança ${ }^{6}$. O infante D. João, sempre saudoso e amoroso na correspondência que trocou com a irmã, mostrou-se igualmente feliz, ao saber da suspeita de gravidez, em carta datada de 14 de outubro ${ }^{7}$. Dias depois, em 21 do mesmo mês, não deixou de recriminar D. Mariana Vitória por ter dado a notícia à mãe de ambos em primeiro lugar ${ }^{8}$.

O nascimento do infante, cujo nome remete para os avós, foi objeto de notícia na Gaceta de Madrid, na qual se pode ler que «um belo infante» chegara ao mundo pelas 00 horas e 15 minutos e que o batismo fora administrado pelo patriarca das Índias. A madrinha fora D. Maria I, representada por Carlos III. Houve Te Deum, luminárias e gala na corte durante três dias. Em Lisboa, o luto por morte de D. Pedro III foi interrompido. A Gazeta de Lisboa publicou a mesma notícia em tradução portuguesa?.

Após o nascimento, o regozijo de todos não oferece surpresas. A correspondência continua com assuntos como as amas, as pequenas enfermidades e o crescimento da criança. Por exemplo, em 28 de julho, D. Maria I expressava alegria por o neto estar «bom e cada vez mais gordo e bonito» ${ }^{10}$. Em meados de agosto, já estava «galante» permitindo que a mãe se divertisse com ele ${ }^{11}$. Para alegria de D. Maria

\footnotetext{
${ }^{4}$ Para Portugal, a correspondência particular com informações sobre as crianças da Casa Real não é abundante. Além da que se cita para o infante, cf. também a que se referiu às rainhas de Portugal D. Mariana Vitória e a D. Carlota Joaquina. Cf., respetivamente, Cartas da rainha D. Mariana Vitória para a sua família de Espanha, ap. e anot. Caetano Beirão (Lisboa: Empresa Nacional de Publicidade, 1936). Alice Lázaro, La Menina: retrato de D. Carlota Joaquina nas cartas familiares. Viagem ao interior da Corte portuguesa 1785-1790 (Lisboa: Chiado Editora, 2011); Carlota Joaquina: cartas inéditas, est. e org. Francisca L. Nogueira de Azevedo (Rio de Janeiro: Casa da Palavra, 2007). Muito interessante é, para a Holanda e para uma época mais recente, a correspondência trocada entre a rainha Guilhermina ainda criança e a sua professora de inglês. Cf. Darling Queen - Dear Old Bones: queen Wilhelmina's correspondence with her English governess Miss Elizabeth Saxton Winter, 1886-1935, ed. Emerentia van Heuven-van Nes (Amesterdão: Amesterdam University Press, 2017), na qual se abordam temas como questões familiares, brincadeiras, divertimentos, animais de companhia, trocas de felicitações no Natal e na Páscoa, agradecimento de presentes e impressões de viagens pela Europa.

${ }^{5}$ Paulo Drumond Braga, D. Pedro III: o rei esquecido (Lisboa: Círculo de Leitores, 2013), 316.

6 Alice Lázaro, Cartas intimas da rainha Dona Maria I para a filha (1785-1787) (Lisboa: Chiado Editora, 2014), 190.

${ }^{7}$ Alice Lázaro, Se saudades matassem... Cartas intimas do infante D. João (VI) para a irmão (1785-1787) (Lisboa: Chiado Editora, 2011), 203.

${ }^{8}$ Lázaro, Cartas, 205.

${ }^{9}$ Gaceta de Madrid 49, 20 de junho de 1786, 403; Suplemento à Gazeta de Lisboa 26, 30 de junho de 1786.

${ }^{10}$ Lázaro, Cartas, 255.

${ }^{11}$ Ibídem, 261.
} 
I, antes do dia 21, havia chegado a Portugal um retrato da criança ${ }^{12}$ e, em carta de 28 de setembro, referiu-se que estava cada vez mais gorda, «como vejo da medida que mandou o Louriçal» ${ }^{13}$, isto é, o 3. ${ }^{\circ}$ marquês de Louriçal, D. Henrique de Meneses, embaixador de Portugal em Madrid. No início de outubro, por carta do dia 5, a rainha de Portugal expressou a pouca apetência que tivera para tratar dos filhos mas a esperança de, no presente, a situação poder ser diferente face a D. Pedro Carlos: «grande gosto tenho que o netinho vá engordando, pois é sinal de boa saúde, e que te divirtas com ele e te vás acostumando a pegar-lhe. Tomara eu poder fazer o mesmo, ainda que, nunca tive muito jeito para isso, mas, agora, como avó, pode ser que tenha mais $\rangle^{14}$. D. Maria I insistia em mostrar desejo de rever a filha e de conhecer o neto. Ora, este último anseio concretizou-se, ainda que de maneira diferente da pretendida pela rainha. Não foi ela que viajou para Espanha, nem sua filha que voltou a Portugal, mas o infante que foi enviado para o reino dos avós maternos, após a morte dos progenitores.

Pouco se sabe sobre as negociações entre a corte espanhola e a corte portuguesa, isto é, entre Carlos IV (1748-1819) e D. Maria I sobre o envio do infante órfão para Portugal ${ }^{15}$. A correspondência diplomática alude com frequência ao débil estado de D. Pedro Carlos ${ }^{16}$. De qualquer modo, tenhamos presente que à data, ou seja, em 1789, o mesmo não era um sucessor demasiado próximo da coroa de Espanha, uma vez que havia vários primos à sua frente. Isto é, seu pai, o infante D. Gabriel, fora o segundo filho na linha sucessória, depois do príncipe Carlos, o futuro Carlos IV, já que Fernando, que será Fernando I das Duas Sicílias, tinha ficado com a herança paterna italiana e fora afastado da espanhola. Por outro lado, apesar de Carlos IV ter tido muitos filhos, em 1788, apenas dois varões tinham sobrevivido, Fernando, o futuro Fernando VII (1784-1833), de Espanha e o infante Carlos Maria Isidro (17881855), pouco mais do que recém-nascido. Em Portugal, o casal constituído pelos príncipes D. João (VI) e D. Carlota Joaquina (1775-1830) ainda não havia consumado o enlace - só o foi em abril de 1790 - nascendo o primeiro filho desta união em 1793, exatamente a infanta D. Maria Teresa de Bragança (Queluz, 29 de abril de 1793 - Triste, 17 de janeiro de 1874) ${ }^{17}$, com quem D. Pedro Carlos se matrimoniará, no Rio de Janeiro, em 1810. Isto é, nesta conjuntura, o infante poderia ser o sucessor da coroa de Portugal e até mesmo da de Espanha, neste caso se os filhos de Carlos IV continuassem a falecer antes de chegar à idade adulta, o que não aconteceu.

\footnotetext{
12 Ibídem, 264. D. João também comentou o retrato: «não era preciso o retrato para se saber que era muito bonito: bastava ser filho de uma mãe tão formosa como tu és e também há-de ser cheio de raras qualidades para imitar em tudo a mãe». Cf. Lázaro, Se saudades, 367.

${ }^{13}$ Lázaro, Cartas, 278.

14 Ibídem, 280.

${ }^{15}$ Matéria que tratamos no livro que estamos a preparar.

${ }^{16}$ Nuno de Castro Luís, Afirmação europeia de uma monarquia transatlântica: estratégias político-diplomáticas nos casamentos dos filhos de D. João VI (Tese de mestrado, Faculdade de Letras da Universidade de Lisboa, 2015), 52-56.

17 Sobre esta figura, cf. Isabel Drumond Braga, "A Parenética Franciscana ao Serviço da Monarquia por Ocasião do Nascimento de D. Maria Teresa de Bragança (1793)”, em Paralellus 6, 12, (2015): 119138. https://www.academia.edu/15099803/ (consultado em 20 de setembro de 2018).
} 
D. Pedro Carlos chegou a Portugal acompanhado por um pequeno séquito no qual se contavam os seus servidores mais diretos, como a aia, D. Maria Madalena de Ruiz Moscozo ${ }^{18}$, e a açafata, D. Cayetana da Vera, além do mestre o padre Francisco Marín ${ }^{19}$. D. Diogo José Vito de Menezes, . $^{\circ}$ conde de Cantanhede e $5 .^{\circ}$ marquês de Marialva (1739-1803) que o conduziu do Caia a Lisboa, em novembro de 1789, não deixou de referir um episódio acerca da expectável estranheza da criança perante desconhecidos:

vinha o Senhor Infante, olhando-me de lado, sem se familiarizar comigo, o que eu, lentamente ia conseguindo, com vários brincos pueris, com que o vinha entretendo, ora de várias carruagens de papel que lhe fazia, e que subiam, como por calçadas, pelas minhas pernas acima, ora com trovas que ele por costume ouvia e a que respondia com muita graça e viveza. Como eu tinha ido ao Caia com farda de brigadeiro, no dia seguinte e em que partimos de Vila Viçosa, perguntou Sua Alteza já à marquesa: 'Onde está aquele homem doirado, que vinha ontem connosco no coche?'. E dizendolhe a marquesa que era eu, continuou: 'Eia, que venha para o coche'. E de ser visto de revés, passei a ser valido ${ }^{20}$.

Os anos que decorreram entre a chegada da criança e a partida do jovem para o Brasil, acompanhando a Corte portuguesa, parecem ter sido marcados por um episódio significativo. A renúncia por parte de D. Pedro Carlos aos bens que constituíam a sua casa, quando completou 20 anos, isto é, 1806. Ora, nessa data, assistia-se à expansão do poder napoleónico que virá a atingir militarmente Portugal, após a assinatura do tratado secreto de Fontainebleau, entre França e Espanha, em 27 de outubro de 1807. Por este acordo, os dois signatários acordaram dividir Portugal e o seu império entre ambos, ao mesmo tempo que a Espanha autorizou a passagem de tropas francesas pelo seu território a fim de invadir Portugal. No que se refere ao espaço europeu, a França e a Espanha dividiram Portugal em três partes. A província de entre Douro e Minho, com capital no Porto, seria para o rei da Etrúria, com o título de reino da Lusitânia Setentrional; o Alentejo e o Algarve ficariam para Godoy, favorito da Corte espanhola e primeiro-ministro durante algum tempo, formando o principado dos Algarves; o destino da terceira parte seria resolvido após o estabelecimento da paz.

Era a resposta à recusa portuguesa do bloqueio continental, decretado por Napoleão, em $1806^{21}$, pelo qual nenhuma nação europeia poderia comerciar ou manter

18 Posteriormente irradiada por apoiar D. Carlota Joaquina e o partido que pretendia afastar o príncipe regente. Cf. Lázaro, Andorinhas e Sabiás, 426.

${ }^{19}$ Ibídem, 426, 444.

${ }^{20}$ Itinerário que fez na augusta condução do Sereníssimo Senhor Infante D. Pedro Carlos de Bragança e Bourbon desde o Caia até Lisboa em novembro de 1789 o marquês de Marialva. D. Diogo José Vito de Menezes, publicado em Lázaro, Andorinhas e Sabiás, 446.

${ }^{21}$ Sobre estes acontecimentos, cf. Jorge Pedreira, Fernando Dores Costa, D. João VI, o Clemente, (Lisboa: Círculo de Leitores, 2006), 120-142. Sobre a conjuntura política deste período, cf. Ana Cristina Bartolomeu de Araújo, “As Invasões Francesas e a Afirmação das Ideias Liberais”, em História de Portugal, 
qualquer tipo de relações com as Ilhas Britânicas. Após a derrota de Trafalgar, a França tentou arruinar economicamente a Inglaterra e, assim, forçá-la a render-se. Portugal, sem pressa de acatar tal ordem, foi notificado em julho de 1807, no sentido de encerrar os portos aos Ingleses, confiscar-lhes os navios e quebrar as relações diplomáticas. Tornou-se claro, para o príncipe regente D. João, que duas opções se colocavam a Portugal: ou aceitava o bloqueio continental, com a consequente perda do império português a favor de Inglaterra, que não hesitaria dele se apropriar, ou mantinha a aliança com aquela, o que significaria a conquista de Portugal pela França e a necessária saída da Corte para o Brasil, ideia que estava presente desde a Guerra dos Sete Anos (1756-1763) e que se clarificara quando o perigo napoleónico começou a tornar-se cada vez mais significativo ${ }^{22}$.

O regente tentou, sem êxito, ganhar tempo. As hesitações diplomáticas revelaram as dificuldades de uma pequena potência ${ }^{23}$. Algumas vozes fizeram ouvir-se, como, por exemplo, a de D. Pedro de Almeida Portugal, 3. ${ }^{\circ}$ marquês de Alorna. Este, por diversas vezes, expressou as suas preocupações acerca da necessidade de apetrechar o exército, de escolher criteriosamente os representantes diplomáticos e advertiu para os perigos que a Espanha e a França representavam para Portugal ${ }^{24}$. Em 1807, tomou todas as providências para se opor às invasões francesas mas sem efeito. Napoleão não cedeu. A 12 de agosto desse ano, os enviados diplomáticos francês e espanhol em Lisboa, Rayneval, e o conde de Campo Alange, respetivamente, apresentaram um ultimato: ou Portugal declarava guerra a Inglaterra, até ao dia 1 de setembro, ou os exércitos franco-espanhóis invadiriam o Reino. Em Londres, o embaixador D. Domingos António de Sousa Coutinho garantia que os Ingleses não molestariam Portugal se este fechasse os portos a Inglaterra, desde que não confiscasse as propriedades inglesas, ao mesmo tempo que informou do oferecimento de uma esquadra para se reunir à portuguesa, caso o príncipe regente tivesse que se ausentar do Reino. Em 22 de outubro, D. João publicou o decreto em virtude do qual se fechavam os portos aos Ingleses, já então a esmagadora maioria dos súbditos britânicos e seus bens tinham saído, sem lhes terem sido cobrados direitos. Dias antes, em 18 de outubro, o exército francês entrara em Espanha.

A fidelidade de D. Pedro Carlos ao príncipe regente D. João (VI), manifestada também anteriormente, em 1805, durante a chamada conspiração dos fidalgos, aparentemente não alheia a D. Carlota Joaquina, irá valer-lhe a nomeação para Grande

dir. José Mattoso, v. 5 (O Liberalismo), coord. Luís Reis Torgal e João Lourenço Roque, (Lisboa: Estampa, 1998), 21-40. Sobre esta matéria, cf. ainda História Geral da Civilização Brasileira, dir. Sérgio Buarque de Holanda e Pedro Moacyr de Campos, 2 (O Brasil Monárquico), 9. a ed. (Rio de Janeiro: Bertrand Brasil, 2003), 76-80; Jurandir Malerba, A Corte no Exilio. Civilização e Poder no Brasil às Vésperas da Independência (1808-1821) (São Paulo: Companhia das Letras, 2000), 197-203.

22 A ideia de tornar o Brasil o centro do Império português apareceu várias vezes ao longo da Época Moderna. Cf., por exemplo, Jorge Pedreira, Fernando Dores Costa, D. João VI, 143. Entre os opositores da ideia, contaram-se pessoas como a rainha D. Carlota Joaquina. Cf. Francisca L. Nogueira de Azevedo, Carlota Joaquina na Corte do Brasil (Rio de Janeiro: Civilização Brasileira, 2003).

${ }^{23}$ Pedreira, Costa, D. João VI, 74-75.

${ }^{24}$ Veja-se a correspondência dos anos de 1804 e 1806 publicada por Ângelo Pereira, D. João VI Príncipe e Rei, 1 (Lisboa: Empresa Nacional de Publicidade, 1953), 138-142, 152-153. 
Almirante-General da Marinha Portuguesa, em 13 de maio de 1808, um cargo criado exclusivamente para o infante, então com 21 anos; e o casamento com a sua primogénita. Efetivamente, a princesa sua prima e tia tinha claro interesse no poder e terá visto o primo e sobrinho como um opositor, ainda que discreto, em especial no que se referiu aos direitos da coroa espanhola após o aprisionamento pelos franceses dos monarcas seus pais, Carlos IV e Maria Luísa de Parma. Não obstante, o infante chegou a apoiar a futura rainha de Portugal nas suas pretensões de exercer a autoridade paterna, na qualidade de regente, nos domínios espanhóis americanos ${ }^{25}$.

O regente D. João (VI), ao nomear D. Pedro Carlos para almirante general da marinha, demonstrou-lhe confiança e apreço e aludiu aos conhecimentos do infante naquela matéria ${ }^{26}$. Contudo, esta deliberação esvaziou o cargo de major-general da armada e a ação desempenhada nem sempre parece ter sido pacífica ${ }^{27}$. Para o seu mentor, José Maria Pereira Dantas, o infante levou a efeito uma ação reformadora em áreas como a real fazenda da marinha, o arsenal, a construção de diques, a fundação de uma cordoaria, de uma biblioteca e de uma academia naval, sem esquecer cuidados com a armada que transportara a família real, regulação dos pagamentos aos seus dependentes e melhoramentos nos portos ${ }^{28}$. Em 1808, D. Rodrigo de Sousa Coutinho, conde de Linhares, considerou em carta, que o infante, era muito ativo, zeloso, diligente e bastante mais dotado do que se pudera imaginar ${ }^{29}$.

O casamento de D. Pedro Carlos e de D. Maria Teresa, ocorrido em 13 de maio de 1810, inaugurou, da melhor maneira, uma série de celebrações familiares da Casa Real na América ${ }^{30}$. Em 16 de maio, a Gazeta do Rio de Janeiro referia-se eufemisticamente a Napoleão e anunciava o desposório e como «novo penhor de felicidade futura da Europa, pois o monstro que para nos subjugar e aniquilar necessita destruir o ilustre sangue dos Bourbons vê cada dia mais frustradas as suas esperanças» ${ }^{31}$. Em 7 de novembro, as festas do casamento, que decorreram a partir de 12 de outubro, ocuparam diversas páginas. Foram referidos vários espetáculos, tais como um curro com carros onde se dançava - cada carro fora oferecido por um ou vários ofícios touros, cavalhadas e fogo-de-artifício. O intendente geral da polícia mandou fornecer

\footnotetext{
${ }^{25}$ Sobre estas matérias, cf. Sara Marques Pereira, D. Carlota Joaquina e os 'Espelhos de Clio': actuaşão política e figurações historiográficas (Lisboa: Livros Horizonte, 1999), 79-119; Pedreira, Costa, D. João VI, 187-191, 204-206; António Ventura, Carlota Joaquina (1775-1830) (Lisboa: Círculo de Leitores, 2011), 86-88; Lázaro, Andorinhas e Sabiás, 377-455.

${ }^{26}$ Silva, A Real Companbia, 147-149.

27 Ibídem, 149.

${ }^{28}$ José Maria Pereira Dantas, Elogio historico do Senhor D. Pedro Carlos de Bourbon e Braganca, infante de Hespanha, e Portugal: almirante general da marinha portugueza, composto e oferecido à muito augusta princeza a Senhora D. Maria Thereza, viuva do mesmo Senhor (Rio de Janeiro: Impressão Régia, 1813), 11-27.

29 Andrée Mansuy-Diniz Silva, Portrait d'un homme d'État: D. Rodrigo de Sousa Coutinho, conte de Linhares (1755-1812), v. 2 (Paris: Centre Culturel Calouste Gulbenkian, 2006), 589.

30 Sobre o casamento, cf. Luiz Gonçalves dos Santos, Memórias para servir à história do reino do Brasil, 1 (Belo Horizonte: Itatiaia, 1981), 250-258, 262-269; Luís, Afirmação europeia, 59-65.

${ }^{31}$ Gazeta do Rio de Janeiro, 39, 16 de maio de 1810.
} 
os camarotes dos que assistiam na praça de Santa Ana com «doces e refrescos com abundância e delicadeza», nas tardes dos dias 12 a 17 e $21^{32}$.

Em breve, a princesa esperava descendência: D. Sebastião de Bourbon e Bragança, infante de Espanha (Rio de Janeiro, 4 de novembro de 1811 - Pau (França), 14 de fevereiro de 1875) ${ }^{33}$. No final de outubro de 1811, segundo Luís Joaquim dos Santos Marrocos, no Rio de Janeiro, havia-se publicado o «Bando Real para o nascimento do futuro menino ou menina, que gozará da alta preeminência de Infante, não obstante não ser filho de infante português; e deseja-se muito que seja menina para a seu tempo haver outro casamento com o nosso infantezinho [D. Miguel] $\rangle^{34}$. Dias depois, acrescentou: «supõe-se que o sobredito parto é para o princípio de novembro e por isso fervem os preparos estrondosos, assim em terra, como no mar, as preces amotinam os ouvidos e todos os pretendentes estão à mira desse tão desejado dia» ${ }^{35}$. O nascimento teve lugar alguns dias depois e o batizado ocorreu em 17 de dezembro, coincidindo com o aniversário de $\mathrm{D}$. Maria $\mathrm{I}^{36}$. O regente determinou que gozasse do título e tratamento de infante, por decreto de 9 de dezembro ${ }^{37}$. Era o primeiro membro da família real a nascer na América. O padre Luís Gonçalves dos Santos escreveu «O primeiro no Novo Mundo. Ditoso Brasil! E mais ditoso ainda Rio de Janeiro! ${ }^{38}$.

D. Pedro Carlos e D. Maria Teresa entendiam-se muito bem, chegando, no princípio de abril de 1812, a referir-se os eventuais excessos do «exercício conjugal», como responsáveis pela doença do infante. De tal forma que os cônjuges foram separados, suspeitando-se que a princesa estivesse de novo grávida ${ }^{39}$. No entanto, outras fontes coevas referiram que a saúde do infante não seria a melhor, em especial desde 1797, data a partir da qual sofrera de bexigas e de um ataque de epilepsia ${ }^{40}$. Sabese, igualmente que, desde criança, manifestara alguns problemas de saúde.

$\mathrm{O}$ infante veio a falecer, na quinta da Boa Vista, às 18 horas e 37 minutos, do dia 26 de maio de $1812^{41}$, apesar de a 23 ainda se acreditar no seu restabelecimento ${ }^{42}$. A Gazeta do Rio de Janeiro deu a «infausta notícia da prematura morte» e informou acerca da determinação do regente, tio e sogro do infante, que decretou seis meses de luto, aliviado nos últimos três ${ }^{43}$. Em 29, ocorreu a celebração de sumptuosas cerimónias

\footnotetext{
${ }^{32}$ Gazeta do Rio de Janeiro, 89, 07 de novembro de 1810.

${ }_{33}$ Gazeta do Rio de Janeiro 89, 06 de novembro de 1811; Santos, Memórias, 286-289-294; Ângelo Pereira, As Senhoras Infantas filhas d'El-Rei D. João VI, fac-símile da edição de 1938 (Lisboa: Ex-Libris, 2004), 4155.

34 Luís Joaquim dos Santos Marrocos, Cartas do Rio de Janeiro 1811-1821 (Lisboa: Biblioteca Nacional, 2008), 85-86.

35 Marrocos, Cartas do Rio de Janeiro, 88.

36 A madrinha foi a Rainha D. Maria I, representada pela nora e o padrinho, o regente. Cf. Gazeta do Rio de Janeiro 101, 18 de dezembro de 1811 e Gazeta Extraordinária do Rio de Janeiro 30, 19 de dezembro de 1811.

37 Gazeta do Rio de Janeiro 98, 17 de dezembro de 1811.

38 Santos, Memorias, 287.

${ }^{39}$ Marrocos, Cartas do Rio de Janeiro, 118.

${ }^{40}$ Pereira, Elogio bistorico, 5.

${ }^{41}$ Gazeta do Rio de Janeiro 44, 30 de maio de 1812.

${ }^{42}$ Marrocos, Cartas do Rio de Janeiro, 129.

43 Gazeta do Rio de Janeiro 44, 30 de maio de 1812.
} 
fúnebres, que implicaram a pregação de vários sermões, Luís Joaquim dos Santos Marrocos comentou que, ao contrário do que antes afirmara, a infanta não estava grávida $^{44}$. A Gaceta de Madrid noticiou o passamento no final de setembro. A regência decretou luto por três meses, rigoroso durante o primeiro ${ }^{45}$.

Foi sepultado no convento de Santo António, do Rio de Janeiro ${ }^{46}$. As exéquias tiveram lugar em 29 de maio e foram amplamente noticiadas na Gazeta do Rio de Janeiro. Pelas 20 horas e 45 minutos, o féretro saiu do palácio da quinta da Boa Vista rumo ao convento de Santo António em coche, acompanhado pelas autoridades militares, civis e eclesiásticas, nobreza e servidores. Foi recebido no adro da igreja por diversas irmandades e após ter sido incensado e acompanhado pelos religiosos ficou depositado na capela do Senhor da Paciência ${ }^{47}$. Por vários pontos do reino foram celebradas exéquias, à medida que a notícia ia sendo conhecida ${ }^{48}$. Anos depois, em 1817, o infante teve um novo túmulo, de mármore com o seu busto, proveniente de Portugal. A mudança ocorreu de noite, após ter sido reconhecido o corpo. $\mathrm{Na}$ igreja foram entoadas as matinas e os ofícios dos defuntos com responsórios de Marcos Portugal, pelos músicos da real câmara e capela. As cerimónias continuaram no dia seguinte com missa, música do mesmo compositor e oração fúnebre ${ }^{49}$.

2. A figura de D. Pedro Carlos de Bourbon e Bragança mereceu diversos sermões por ocasião da sua morte, quatro dos quais foram impressos, três ainda em 1812 e um outro no ano seguinte, e dois elogios históricos de seus contemporâneos, saídos dos prelos em 1813, um da autoria de Joaquim da Nóbrega Cão d'Aboim, decano da Capela Real do Rio de Janeiro, e um outro de José Maria Dantas Pereira ${ }^{50}$, mestre do infante, capitão-de-mar-e-guerra, comandante da Companhia dos GuardasMarinha e diretor da Academia Real dos Guardas-Marinha. Em todos estes textos, dada a sua natureza, encontram-se referências biográficas e encómios diversos.

\footnotetext{
${ }^{44}$ Marrocos, Cartas do Rio de Janeiro, 131.

45 Gaceta de Madrid 130, 24 de setembro de 1812.

${ }^{46}$ Gazeta do Rio de Janeiro 45, 3 de junho de 1812.

47 Ibídem.

48 Por exemplo, a Gazeta do Rio de Janeiro noticiou que, em São Luís do Maranhão, logo que chegou a notícia da morte do infante, o governador da capitania, Paulo José da Silva Gama, fez celebrar juntamente com o bispo, D. Luís de Brito Homem, «entre o aparato mais pomposo e fúnebre, umas solenes exéquias a que assistiu o senado da câmara, todas as classes de pessoas mais distintas e numeroso concurso de povo». Cf. Gaz̧eta do Rio de Janeiro 22, 17 de março de 1813 e 23, 29 de março de 1813.

49 Gazeta do Rio de Janeiro 26, 29 de março de 1817.

${ }^{50}$ Sobre José Maria Dantas Pereira, cf. Carlos André Lopes da Silva, A Real Companbia e Academia dos Guardas-Marinha: aspetos de uma instituição de ensino na alvorada da profissionalização do oficialato militar (18081839) (Dissertação de mestrado, Universidade Federal do Rio de Janeiro, 2012); Nuno Alexandre Martins Ferreira, A Institucionalização do Ensino da Náutica em Portugal (1779-1807) (Tese de doutoramento, Faculdade de Letras da Universidade de Lisboa, 2013).
} 


\section{Quadro}

Pregadores e locais de pregação pelo falecimento do infante

\begin{tabular}{|c|c|c|c|c|}
\hline Pregador & Ordem & Outros Ofícios e dignidades & $\begin{array}{l}\text { Local da } \\
\text { pregação }\end{array}$ & Igreja \\
\hline $\begin{array}{l}\text { Francisco } \\
\text { de São } \\
\text { Paio (Fr.) }\end{array}$ & $\begin{array}{l}\text { São } \\
\text { Francisco }\end{array}$ & $\begin{array}{l}\text { Pregador régio, examinador } \\
\text { da Mesa da Consciência e } \\
\text { Ordens, teólogo da nunciatura } \\
\text { apostólica, padre da província } \\
\text { da Imaculada Conceição do } \\
\text { Rio de Janeiro e antigo leitor } \\
\text { de eloquência e de teologia } \\
\text { dogmática }\end{array}$ & $\begin{array}{l}\text { Rio de } \\
\text { Janeiro }\end{array}$ & Capela Real \\
\hline $\begin{array}{l}\text { João } \\
\text { Silvério de } \\
\text { Lima }\end{array}$ & $\begin{array}{l}\text { Hábito de } \\
\text { São Pedro }\end{array}$ & $\begin{array}{l}\text { Pregador régio, prior de S. } \\
\text { Julião (Santarém), sócio da } \\
\text { Academia Real das Ciências } \\
\text { de Lisboa }\end{array}$ & Lisboa & $\begin{array}{ll}\text { Igreja de } \\
\text { Nossa } \\
\text { Senhora } \\
\text { dos } \\
\text { Mártires }\end{array}$ \\
\hline $\begin{array}{l}\text { António } \\
\text { Vieira da } \\
\text { Soledade }\end{array}$ & $\begin{array}{l}\text { Hábito de } \\
\text { São Pedro }\end{array}$ & $\begin{array}{lrr}\text { Pregador régio, } & \text { presbítero } \\
\text { secular, professor de sagrada } \\
\text { escritura } & \text { no } & \text { seminário } \\
\text { episcopal, examinador sinodal }\end{array}$ & $\begin{array}{l}\text { Rio de } \\
\text { Janeiro }\end{array}$ & $\begin{array}{l}\text { Igreja de } \\
\text { Santa Rita }\end{array}$ \\
\hline $\begin{array}{l}\text { António da } \\
\text { Rocha } \\
\text { Franco }\end{array}$ & $\begin{array}{l}\text { Hábito de } \\
\text { São Pedro }\end{array}$ & Vigário da vara de Ouro Preto & $\begin{array}{l}\text { Ouro } \\
\text { Preto }\end{array}$ & $\begin{array}{l}\text { Igreja } \\
\text { paroquial }\end{array}$ \\
\hline
\end{tabular}

Em comum, os sermões referiram os antepassados do infante, a sua formação, a fidelidade demonstrada ao príncipe regente D. João (VI) por ocasião da partida para o Brasil, a nomeação para Grande Almirante General da Marinha Portuguesa, o casamento com D. Maria Teresa de Bragança, sua prima; e as qualidades que possuía. Em alguns casos, foram feitas algumas referências à conturbada conjuntura de então.

Nas orações fúnebres foi comum incluir reflexões acerca da morte, da igualdade entre nobres e plebeus perante o juízo final e da impossibilidade de alguém escapar à vontade de Deus. Neste pequeno universo, também assim aconteceu. Frei Francisco de São Paio considerou, «a vida dos príncipes, assim como a dos povos, depende da Sua vontade omnipotente e, quando lhe apraz, Ele diz aos monarcas mais poderosos 'entrega-me a purpura e o cetro que Eu te confiei, Eu sou o teu rei e o teu juízo»» ${ }^{51}$. Por seu lado, António Vieira da Soledade foi mais prolixo e considerou a morte:

${ }^{51}$ Frei Francisco de São Paio, Oração funebre que nas exequias mandadas faz̧erpor Sua Alteza Real, o Principe Regente Nosso Senhor ao Serenissimo Senhor D. Pedro Carlos de Bourbon e Bragança, infante de Hespanha, recitou na capela real... (Rio de Janeiro: Impressão Régia, 1812), 5-6. 
voz, que fala a todos sem distinção de estado, de idade e de condição. Os empregos, a autoridade, as riquezas e a grandeza, a mocidade e a saúde tem uma igual sorte, que a sujeição e a pobreza, a enfermidade e a velhice, tudo igualmente acaba no mundo, aniquila-se. A saúde, esse bem tão ufano de si mesmo, nada tem mais sólido do que o nome, a vida é realmente um sonho, a opulência uma sombra que foge, a glória mundana uma figura, e a grandeza mesmo do trono não passa de um exterior brilhante sempre mais fraco do que o tempo, a que o tempo não perdoa ${ }^{52}$.

Apenas um dos pregadores, João Silvério de Lima, cujo sermão teve lugar em Lisboa, na igreja de Nossa Senhora dos Mártires, a pedido da Academia Real das Ciências de Lisboa, tornou clara a decoração do templo, preparado para a celebração na ausência do cadáver, e com recurso à arte efémera ${ }^{53}$; ainda que de forma muito discreta, limitando-se a referir «uma eça lutuosa, ornamentos fúnebres e lúgubres alfaias cobrindo o sagrado templo» ${ }^{54}$.

Nos sermões de exéquias a lista das qualidades reais ou desejadas do defunto foi matéria sempre presente. No caso de D. Pedro Carlos, as referências foram, em parte, afins às dos monarcas. No elenco das virtudes contam-se amabilidade, boa índole, decoro, entendimento (inteligência), generosidade, nobreza e piedade, referenciadas por João Silvério de $\mathrm{Lima}^{55}$, que definiu o infante como «uma alma nobre e generosa, um entendimento perspicaz, estas excelentes qualidades de espírito que se demonstram por virtudes essenciais e ações heroicas e que nos prometem tanto bem e tão cedo perdemos ${ }^{56}$. António da Rocha Franco pronunciou-se sobre as virtudes de D. Pedro Carlos, indicando dignidade, discrição, espirituosidade, honestidade e sisudez, para rematar considerando que era «humano sem afetação, grande sem prejuízo, nobre sem orgulho, príncipe-homem, sua alteza cuidava de temperar a majestade espanhola

\footnotetext{
52 Soledade, Oração, 5.

${ }^{53}$ Sobre este tipo de decorações, cf. Arte Efémera em Portugal, coord. João Castel-Branco Pereira (Lisboa: Fundação Calouste Gulbenkian, 2000). E os estudos de Joaquim Jaime Ferreira Alves, “Cerimónias fúnebres no Porto por D. José (1761-1788), Príncipe do Brasil”, em Genealogia \& Heráldica 5-6, 1, (2001): 471-495, “Cerimónias fúnebres por D. Pedro III (1786)”, em Estudos em Homenagem a João Francisco Marques 1 (Porto: Universidade do Porto, 2001), 439-455; José Manuel Tedim, "Teatro da Morte e da Glória. Representações Fúnebres nas Exéquias de D. João V na Sé de Braga”, em Revista de Ciências Históricas 4, (1989): 281-292, "Festas Barrocas no Brasil Colonial. Exéquias de D. João V em S. Salvador da Baía e S. João d'El-Rei” em Relaciones artísticas entre la Península Ibérica y América. Actas del V Simposio Hispano-Portugués de Historia del Arte (Valladolid: s.n., 1990), 273-276, "Carlo Fontana e as Exéquias de D. Pedro II na Igreja de Santo António dos Portugueses em Roma”, I Congresso Internacional do Barroco: actas 2 (Porto: Reitoria da Universidade do Porto, Governo Civil do Porto, 1991), 503-518, “Aparatos Fúnebres, Ecos Saudosos nas Exéquias de D. Pedro II e D. João V”, em Arte Efémera em Portugal (Lisboa: Fundação Calouste Gulbenkian, 2000), 237-279.

${ }^{54}$ João Silvério de Lima, Oração funebre nas exequias do Serenissimo Senhor Infante Dom Pedro Carlos de Bragança e Bourbon, que fez celebrar a Academia Real das Sciencias na Igreja de Nossa Senhora dos Martyres em Lisboa, recitada por... (Lisboa: Tipografia da mesma Academia, 1813), 3.

${ }^{55}$ Lima, Oração, 10, 12, 26.

56 Ibídem, 5.
} 
com a brandura e suavidade do génio português $\rangle^{57}$. Fidelidade, gratidão, piedade e respeito foram virtudes salientadas por frei Francisco de São Paio ${ }^{58}$. E afabilidade, bondade, caridade, constância, generosidade, graça, gratidão, nobreza, sabedoria, ternura e virtuosidade mencionadas por António Vieira da Soledade, pregador que sistematizou o tema com a frase «qualidades reais sólidas e admiráveis que distinguem os grandes príncipes e que acrescentam à glória do nascimento um novo esplendor que os imortaliza na prosperidade ${ }^{59}$. Este autor espraiou-se ainda em considerações como:

ser grande pelo nascimento, e querer ser ainda maior pela virtude, isto é, preferir a nobreza do espírito à nobreza do sangue; ser rico, e não dar outro uso à sua riqueza, do que o alívio da pobreza, receber respeitos e merecê-los tanto mais quanto tanto menos os exige; possuir tesouros e sacrificá-los à amizade convencido com o sábio, de que vale mais um amigo do que mil tesouros, ou antes, que nada pode compararse com o amigo fiel e que o ouro e a prata não merecem ser postos em balança com a sinceridade da sua fé́ ${ }^{0}$.

Os autores dos elogios históricos também não se abstiveram de listar as qualidades de D. Pedro Carlos. Para José Maria Dantas Pereira, fora: benigno, comedido, liberal, modesto, pacífico, silencioso e singelo ${ }^{61}$, enquanto Joaquim da Nóbrega Cão d'Aboim salientou o amor às letras, as habilidades manuais «porque era em todas tão previsto e experimentado como se fosse um perfeito artesão», a par das facetas de esmoler, recatado e discreto ${ }^{62}$.

Ao longo dos sermões, os pregadores não raramente faziam referências a figuras do Antigo Testamento, imperadores e reis, com o intuito de enaltecer o defunto. No caso de D. Pedro Carlos as comparações foram feitas com David, Jóas e Jónatas, por Frei Francisco de São Paio; Jacob, Salomão e Zaqueu, por António Vieira da Soledade, Abraão, David, Elias, Germânico, D. João III, Jóas, Jónatas, Marco Aurélio, Moisés e Tito, por António da Rocha Franco. Isto é, possível unificador da Península Ibérica, como David que uniu Israel e como o general romano Germânico, que foi herdeiro imperial; exemplo em negativo de Jacob, pois viveu pouco; próspero e cobiçado como Jóas, rei de Judá, e Zaqueu, cobrador de impostos; pacífico como o rei

57 António da Rocha Franco, Oração Funebre que nas Solemnes Exequias celebradas em memoria do Serenissimo Senhor D. Pedro Carlos de Bourbon e Bragança, infante de Hespanha, e almirante general da Marinha Portugueza, recitou na parochial de Ouro Preto de Villa Rica, no dia 8 de julho de 1812, presentes o Ex. ${ }^{\text {mo }}$ Conde da Palma, governador e capitão general daquela capitania, camara, nobreza e clero (Rio de Janeiro: Impressão Régia, 1812), 8.

58 São Paio, Oração, 6-9.

${ }^{59}$ Soledade, Oração, 6-11.

${ }^{60}$ Ibídem, 11.

${ }^{61}$ Pereira, Elogio Historico, 28.

${ }^{62}$ Joaquim da Nóbrega Cão d'Aboim, Elogio Historico do Serenissimo Senhor Infante D. pedro Carlos de Burbon e Braganç, almirante general da Armada Real portuguesa, composto e dedicado ao Principe Nosso Senhor, o Senhor Dom João, principe regente de Portugal e das conquistas por... (Rio de Janeiro: Impressão Régia, 1813), 12-18. 
D. João III, o único português referenciado; Salomão e os imperadores Marco Aurélio e Tito e bom cristão e dádiva de Deus como o profeta Elias e Jónatas, um dos filhos do rei Saul e amigo do rei David.

Os pregadores, embora sem se deterem muito na genealogia do infante falecido, não deixaram de referir os seus ilustres antepassados das casas de Bourbon e de Bragança, designadamente os pais e os avós. Tais foram os casos de António da Rocha Franco $^{63}$, António Vieira da Soledade ${ }^{64}$, e João Silvério de Lima ${ }^{65}$. Frei Francisco de São Paio chegou a pregar que D. Pedro Carlos fora o fruto único do casamento dos pais ${ }^{66}$, esquecendo que haviam nascido os infantes Maria Carlota (1787) e Carlos José António (1788) que não sobreviveram.

Dado que as orações fúnebres frequentemente fazem pequenas biografias do falecido, não é de estranhar que os pregadores tenham aludido à formação do infante. Se João Silvério de Lima se referiu ao primeiro mestre e confessor, o padre Francisco Marín, e a José Maria das Antas Pereira, sócio da Academia Real das Ciências de Lisboa, como seu professor e mentor ${ }^{67}$, António da Rocha Franco optou por referir questões mais pontuais, afirmando que fora educado «debaixo das vistas e tutela da sua augusta avó» e que o paço de D. Maria I fora a sua escola ${ }^{68}$, enquanto frei Francisco de São Paio fez um elenco das matérias que estudou nele incluindo eloquência, filosofia, geografia, história, línguas estrangeiras não discriminadas, matemática e pintura. A história mereceu-lhe um comentário mais extenso do que as restantes matérias, de acordo com as conceções da época. Repare-se que, neste âmbito, incluiu mesmo uma lista de qualidades indispensáveis a quem detivesse o poder, ou algum poder:

a história apresentando-lhe seus grandes homens parecia dizer-lhe: 'Príncipe, escolhe nesta galeria os modelos que te hão-de dirigir, imita suas virtudes, e foge dos vícios que ali encontrares. Tu és objeto das vistas do público, eu não perdoarei teus defeitos, vê que te espera a lisonja, esta antiga cortesã sempre infiel à verdade; ela poderá incensar teus crimes, mas não te poderá defender do meu juízo, tu és mortal, eu nunca morro, a minha censura ou o meu elogio durará tanto como os séculos. Se fores justo, sensível, generoso, bom amigo, bom pai, eu levarei teu nome até à última posteridade ${ }^{69}$.

No Elogio Historico, da autoria de José Maria Dantas Pereira, foi feito o elenco das matérias que tinham sido objeto de ensino, a saber, botânica, físico-química, francês, geografia, história de Espanha, história geral, matemáticas puras, com exceção do cálculo superior; noções elementares de artilharia, de cosmografia, de mecânica, e da evolução da cavalaria e da infantaria, todas lecionadas pelo autor do elogio; a par de

\footnotetext{
${ }^{63}$ Franco, Oração, 9.

${ }^{64}$ Soledade, Oração, 10.

${ }^{65}$ Lima, Oração, 8-9.

${ }^{66}$ São Paio, Oração, 10.

${ }^{67}$ Lima, Oração, 9, 17.

${ }^{68}$ Soledade, Oração, 6-7.

${ }^{69}$ São Paio, Oração, 13.
} 
dança, esgrima, desenho e inglês, matérias ensinadas por outros mestres ${ }^{70}$. O domínio do latim era de molde a permitir a D. Pedro Carlos a tradução de uma das obras de Tácito (97 d.C.- após 117), um senador, cônsul e historiador romano, trabalho que acabara de iniciar ${ }^{71}$. No Elogio Historico, escrito por Joaquim da Nóbrega Cão d'Aboim, a ênfase foi dada à formação inicial e a matérias como gramática, retórica, filosofia racional e experimental, matemática, história, jurisprudência, náutica e até artes mecânicas ${ }^{72}$. Os passatempos do infante foram lembrados apenas por José Maria Dantas Pereira, a saber, caça, jardinagem, horticultura, passeios, teatro e torno ${ }^{73}$.

D. Pedro Carlos foi, como já se referiu, criado em Portugal junto da avó e do tio materno e todos os pregadores salientaram a fidelidade e a gratidão do infante para com a família materna que o acolheu. Frei Francisco de São Paio enfatizou que Portugal fora «asilo à inocência do príncipe» ${ }^{74}$ e que este fora sempre um fiel seguidor do exemplo do regente D. João (VI), considerando ainda que «desde o momento em que a Espanha o entregou nos braços de Portugal, a nação viu a fiel correspondência com que ele se mostrou sempre grato à protetora mão que dirigia a marcha da sua infância, fazendo-lhe ignorar a morte dos príncipes seus pais» ${ }^{75}$, enquanto António Vieira da Soledade lembrou que o infante encontrara em Portugal dois novos pais, os «pais de amon» ${ }^{76}$.

A conjuntura política não ficou omissa da parenética ${ }^{77}$. Os pregadores recordaram sucintamente alguns dos problemas vividos para valorizar a opção de D. Pedro Carlos, então com 22 anos, no sentido de se manter com a família materna e partir para o Brasil, desprezando eventuais posições favoráveis em Espanha. Logo em 1801, com o ataque a Olivença, foram expulsos os espanhóis residentes em Portugal, entre os quais se contaram vários servidores domésticos do infante, então com 15 $\operatorname{anos}^{78}$. Posteriormente, ainda antes de ser conhecido o destino que Napoleão pretendia dar a Espanha, D. Pedro Carlos ignorou o apelo do poder e manteve-se fiel a Portugal, apesar das agruras da viagem para o Brasil e do clima do destino (perigos marítimos, incómodos de uma travessia prolongada, um clima diferente), referidas em alguns sermões.

Frei Francisco de São Paio recordou que o infante «via a sua pátria mostrandolhe o trono dos seus maiores, o berço do seu nascimento, o túmulo de seus pais e a fortuna sobre montes de ouro, antigos alicerces da Casa do Infantado» ${ }^{79}$, porém,

${ }^{70}$ Pereira, Elogio Historico, 6.

71 Ibídem, 7.

${ }^{72}$ Cão d'Aboim, Elogio Historico, 12.

73 Pereira, Elogio Historico, 5.

${ }^{74}$ São Paio, Oração, 10.

75 Ibídem, 6.

${ }^{76}$ Soledade, Oração, 13.

77 Para esta época, cf. igualmente João Francisco Marques, “O Clero Nortenho e as Invasões Francesas” em Obra Selecta 1 (Lisboa: Roma Editora, 2008), 67-144, especialmente 91-93 e 100-103, José Marinho Afonso Álvares, A Parenética Portuguesa e os Principais acontecimentos Políticos de 1820 a 1834, (Coimbra: Dissertação de Licenciatura, Faculdade de Letras da Universidade de Coimbra, 1966).

78 São Paio, Oração, 14-15.

${ }^{79}$ Ibídem, 17. 
“desprezou tudo quanto lhe dera a fortuna, desprezou a voz da pátria, as ameaças da lei, porque nem a fortuna nem a pátria, nem a lei lhe podiam dar um coração como o de seu augusto tio" $"$. No mesmo sentido foram as palavras de António da Rocha Franco, ao defender que D. Pedro Carlos «sabe que não são os grandes Estados que fazem os grandes príncipes. Que delibera pois? Expor-se à bravura dos mares, ao perigo das tempestades, à discrição dos ventos, antes que separar-se do príncipe que o ama, o preza, o distingue» ${ }^{81}$. Por seu lado, António Vieira da Soledade defendeu igualmente que a atitude do infante demonstrou a sua grandeza de carácter:

ensina ao mundo político e religioso que há um tempo em que é preferível o sacrifício à tranquilidade, o risco de vida às comodidades da mesma vida, os contratempos à serenidade, os infortúnios às delícias e as privações à abundância, e vem o ser o tempo em que a justiça, a razão e a política e a religião unanimemente nos pedem as provas do devido amor e gratidão ${ }^{82}$.

A escolha para Grande Almirante General da Marinha Portuguesa, por parte do príncipe regente, em 20 de junho de 1808, apareceu, pela voz dos pregadores como uma recompensa pela fidelidade demonstrada, ao mesmo tempo que não ignoraram a preparação prévia em matérias como a matemática, entendida como coadjuvante a uma boa preparação para o desempenho do cargo $^{83}$. Na sequência desta questão, não raramente, foi lembrado que o infante não tivera oportunidade de demonstrar perícia em matéria de guerra, o que não deveria ser entendido como um defeito.

Escassas menções foram feitas ao casamento com D. Maria Teresa de Bragança, realizado no Rio de Janeiro, em 13 de maio de 1810. Porém, nos sermões, ainda que escassamente, encontram-se alusões à conjuntura política e às matérias religiosas da época. João Silvério de Lima criticou os ateus e pregou:

santa religião que professo, tu me sustentas, tu aquietas meu coração, e meu espírito de outro modo, e somente nos limites da presente vida, como o ímpio crê, abismado em dor e dessolado, e tocando de perto os termos fatais de uma aniquilação, que desespera. Excede o senso comum e parece impossível, que tão satisfeitos vivam e tão aflitos morram os que só creem na vida presente, e somente a ela reduzam a sua existência ${ }^{84}$.

Em outro momento do sermão, recordou a saída da família real rumo ao Brasil: «dias de agitação, consternados e aflitos dias, cheios de perturbação e agonia, em que o príncipe houve de retirar-se dos seus reinos neste continente e de passar-se aos seus estados do Brasil, no continente da América! Portugal nunca os viu nem mais

\footnotetext{
${ }^{80}$ Ibídem, 18.

${ }^{81}$ Franco, Oração, 13.

82 Soledade, Oração, 18.

${ }^{83}$ Franco, Oração, 18, Soledade, Oração, 14, São Paio, Oração, 19-20.

${ }^{84}$ Lima, Oração fúnebre, 4.
} 
tormentosos, nem mais incertos» ${ }^{85}$. O mesmo tema foi abordado pelo padre António da Rocha Franco que, ao referir-se a Napoleão e às invasões francesas, o fez de forma eufemística, tal como outros pregadores da época ${ }^{86}$ :

A guerra, o monstro da guerra, tem estendido suas asas sobre a Europa, o seu trovão tem abalado os tronos e posto em concussão as monarquias. Uma funesta revolução dos tempos torna a trazer-nos a frenética idade dos Vândalos, a paz levantou da terra o seu voo, a violação dos direitos mais sagrados das gentes se apelidou de liberdade, a simulação de política, e de direito a força. O rei não está seguro no seu trono [...]. O nosso soberano, este príncipe amabilíssimo, para poupar o sangue e as vidas dos seus, é precisado a abandonar a mais bela, a princesa das cidades, para vir asilar-se aquém dos mares, a um país, que não armas, mas o engenho e talentos de Colombo granjearam a seus avós ${ }^{87}$.

D. Pedro Carlos de Bourbon e Bragança, nascido em Espanha, criado em Portugal e falecido no Brasil, viveu numa época conturbada marcada pela revolução francesa e pelo avanço napoleónico, foi um dos protagonistas do primeiro casamento de um membro da realeza no Brasil, pai do primeiro infante a nascer na América e igualmente o primeiro membro da Casa Real a perecer nessa parte do império português. A parenética que se publicou - muito mais escassa do que a que se pregou - na tipologia de João Francisco Marques, pregação extraordinária incluída no subgénero encomiástico, no caso concreto orações fúnebres ${ }^{88}$, não obstante ser, sem surpresa, laudatória e memorialística, não deixa de traçar imagens de referência de um infante das casas de Bourbon e Bragança.

85 Ibídem, 5.

${ }^{86}$ Esta prática foi comum a outros pregadores, cf. Isabel Drumond Braga, "Chorar uma Rainha em Portugal e no Brasil: os Sermões por Ocasião da Morte de D. Maria I”, em Anais do I Congresso Lusófono de Ciência das Religiões - Religiões e Espiritualidades, Culturas e Identidades, dir. Paulo Mendes Pinto, Carlos Andrade Cavalcanti, Sérgio Junqueira e Eulálio Figueira, vol. 3 (A Parenética ao Serviço da Coroa: do Brasil Colónia ao Brasil Imperial), coord. Isabel Drumond Braga, Maria Renata Duran e Andrea Doré (Lisboa: Edições Universitárias Lusófonas, 2015) 38-59, https://www.academia.edu/25914120/ (consultado em 2 de outubro de 2018).

${ }^{87}$ Franco, Oração funebre, 12.

${ }^{88}$ Sobre a tipologia, cf. João Francisco Marques, "Oratória Sacra ou Parenética” Dicionário de História Religiosa de Portugal, 4, dir. Carlos Moreira de Azevedo (Lisboa: Universidade Católica Portuguesa, Centro de Estudos de História Religiosa, 2001), 470-510. Sobre a oratória fúnebre em Portugal, cf. Braga, Chorar; Braga, A Parenética e a bibliografia aí citada. Sobre a oratória fúnebre em outros espaços europeus, cf., por exemplo, Romano Allemano, Oratori Sacri del Seicento. Antologia di Temi e di Motivi dell'Eloquenza Religiosa Barroca, (Turim, Tesi di Laura in Litteratura Italiana, Università degli Studi di Torino, Facultà di Lettere e Filosofia, 1968), 423-433, Bruno Petey-Girard, "Parler des morts, parler de soi. Remarques sur la place du sujet dans les harangues funèbres", em De bonne vie s'ensuit bonne mort. Récits de mort, récits de vie en Europe (XVe- XVII siècle), dir. Patricia Eichel-Lojkine (Paris: Honoré Champion, 2006), 169-182, Jeanne Shami, "Women and Sermons", em The Oxford Handbook of the Early Modern Sermon, dir. Peter McCullought, Hugh Adlington e Emma Rhatigan (Oxford: Oxford University Press, 2011), 155-177. 


\section{FONTES E BIBLIOGRAFIA}

\section{Fontes Impressas}

Carlota Joaquina: cartas inéditas, est. e org. Francisca L. Nogueira de Azevedo (Rio de Janeiro: Casa da Palavra, 2007).

Cartas da rainha D. Mariana Vitória para a sua familia de Espanha, ap. e anot. BEIRÃO, Caetano Cartas da Rainha D. Mariana Vitória para a sua familia de Espanha (Lisboa: Empresa Nacional de Publicidade, 1936).

D’aboim, Joaquim da Nóbrega Cão, Elogio Historico do Serenissimo Senhor Infante D. pedro Carlos de Burbon e Bragança, almirante general da Armada Real portuguesa, composto e dedicado ao Principe Nosso Senhor, o Senhor Dom João, principe regente de Portugal e das conquistas por... (Rio de Janeiro: Impressão Régia, 1813).

Dantas, José Maria Pereira, Elogio historico do Senhor D. Pedro Carlos de Bourbon e Bragança, infante de Hespanha, e Portugal: almirante general da marinha portugueza, composto e oferecido à muito augusta princeza a Senhora D. Maria Thereza, viuva do mesmo Senhor (Rio de Janeiro: Impressão Régia, 1813).

Darling Queen - Dear Old Bones: queen Wilhelmina's correspondence with her English governess Miss Elizabeth Saxton Winter, 1886-1935, ed. Emerentia van Heuven-van Nes (Amesterdão: Amesterdam University Press, 2017).

Franco, António da Rocha, Oração Funebre que nas Solemnes Exequias celebradas em memoria do Serenissimo Senhor D. Pedro Carlos de Bourbon e Bragança, infante de Hespanba, e almirante general da Marinha Portugueza, recitou na parocbial de Ouro Preto de Villa Rica, no dia 8 de julho de 1812, presentes o Ex." ${ }^{m}$ Conde da Palma, governador e capitão general daquela capitania, camara, nobreza e clero (Rio de Janeiro: Impressão Régia, 1812).

Gaceta de Madrid 130, 24 de setembro de 1812.

Gaceta de Madrid 49, 20 de junho de 1786, 403.

Gazeta do Rio de Janeiro, 39, 16 de maio de 1810.

Gaz̧eta do Rio de Janeiro, 89, 07 de novembro de 1810.

Gazeta do Rio de Janeiro 89, 06 de novembro de 1811.

Gazeta do Rio de Janeiro 98, 17 de dezembro de 1811. 
Gazeta do Rio de Janeiro 101, 18 de dezembro de 1811.

Gazeta do Rio de Janeiro 44, 30 de maio de 1812.

Gazeta do Rio de Janeiro 45, 03 de junho de 1812.

Gazeta do Rio de Janeiro 22, 17 de março de 1813.

Gaz̧eta do Rio de Janeiro 23, 29 de março de 1813.

Gaz̧eta do Rio de Janeiro 26, 29 de março de 1817.

Gazeta Extraordinária do Rio de Janeiro 30, 19 de dezembro de 1811.

Lázaro, Alice, Andorinhas e Sabiás: os casamentos em Espanha das filhas de D. João VI (18101823) (Lisboa: Chiado Editora, 2018).

Lázaro, Alice, Cartas intimas da rainba Dona Maria I para a filha (1785-1787) (Lisboa: Chiado Editora, 2014).

Lázaro, Alice, La Menina: retrato de D. Carlota Joaquina nas cartas familiares. Viagem ao interior da Corte portuguesa 1785-1790 (Lisboa: Chiado Editora, 2011).

Lázaro, Alice, Se saudades matassem...Cartas intimas do infante D. João (VI) para a irmão (1785-1787) (Lisboa: Chiado Editora, 2011).

Lima, João Silvério de, Oração funebre nas exequias do Serenissimo Senhor Infante Dom Pedro Carlos de Bragança e Bourbon, que fez celebrar a Academia Real das Sciencias na Igreja de Nossa Senhora dos Martyres em Lisboa, recitada por... (Lisboa: Tipografia da mesma Academia, 1813).

Marrocos, Luís Joaquim dos Santos, Cartas do Rio de Janeiro 1811-1821 (Lisboa: Biblioteca Nacional, 2008).

Santos, Luiz Gonçalves dos, Memórias para servir à história do reino do Brasil, 1 (Belo Horizonte: Itatiaia, 1981).

São Paio, Frei Francisco de, Oração funebre que nas exequias mandadas faz̧er por Sua Alteza Real, o Principe Regente Nosso Senhor ao Serenissimo Senhor D. Pedro Carlos de Bourbon e Bragança, infante de Hespanha, recitou na capela real... (Rio de Janeiro: Impressão Régia, 1812). 
Soledade, António Vieira da, Oraşão Funebre que nas Exequias do Serenissimo Senhor D. Pedro Carlos de Bourbon e Bragança, Almirante General da Marinha Portugueza junto à Real pessoa, recitou na igreja de Santa Rita desta Corte, no dia 8 de julbo do anno de 1812 ..., (Rio de Janeiro: Impressão Régia, 1812).

Suplemento à Gazeta de Lisboa 26, 30 de junho de 1786.

\section{Estudos}

Allemano, Romano, Oratori Sacri del Seicento. Antologia di Temi e di Motivi dell'Eloquenza Religiosa Barroca, (Turim, Tesi di Laura in Litteratura Italiana, Università degli Studi di Torino, Facultà di Lettere e Filosofia, 1968).

Álvares, José Marinho Afonso, A Parenética Portuguesa e os Principais acontecimentos Politicos de 1820 a 1834, (Coimbra: Dissertação de Licenciatura, Faculdade de Letras da Universidade de Coimbra, 1966).

Alves, Joaquim Jaime Ferreira, “Cerimónias fúnebres no Porto por D. José (17611788), Príncipe do Brasil”, em Genealogia \& Heráldica 5-6, 1 (2001), 471-495.

Alves, Joaquim Jaime Ferreira, "Cerimónias fúnebres por D. Pedro III (1786)", Estudos em Homenagem a João Francisco Marques 1 (Porto: Universidade do Porto, 2001), 439-455.

Araújo, Ana Cristina Bartolomeu de, "As Invasões Francesas e a Afirmação das Ideias Liberais”, em História de Portugal, dir. José Mattoso, v. 5 (O Liberalismo), coord. Luís Reis Torgal e João Lourenço Roque, (Lisboa: Estampa, 1998), 21-40.

Arte Efémera em Portugal, coord. João Castel-Branco Pereira (Lisboa: Fundação Calouste Gulbenkian, 2000).

Azevedo, Francisca L. Nogueira de, Carlota Joaquina na Corte do Brasil (Rio de Janeiro: Civilização Brasileira, 2003).

Braga, Isabel Drumond, "A Parenética Franciscana ao Serviço da Monarquia por Ocasião do Nascimento de D. Maria Teresa de Bragança (1793)", em Paralellus 6, 12, (2015) 119-138. https://www.academia.edu/15099803/ (consultado em 20 de setembro de 2018). https://doi.org/10.20426/P.2178$\underline{8162.2015 \mathrm{v} 6 \mathrm{n} 12 \mathrm{p} 119}$

Braga, Isabel Drumond, "Chorar uma Rainha em Portugal e no Brasil: os Sermões por Ocasião da Morte de D. Maria I”, em Anais do I Congresso Lusófono de Ciência das Religiões - Religiões e Espiritualidades, Culturas e Identidades, dir. Paulo Mendes Pinto, Carlos Andrade Cavalcanti, Sérgio Junqueira e Eulálio Figueira, vol. 3 ( $A$ Parenética ao Serviço da Coroa: do Brasil Colónia ao Brasil Imperial), coord. Isabel 
Drumond Braga, Maria Renata Duran e Andrea Doré (Lisboa: Edições Universitárias Lusófonas, 2015) 38-59, https://www.academia.edu/25914120/ (consultado em 2 de outubro de 2018).

Braga, Paulo Drumond, D. Pedro III: o rei esquecido (Lisboa: Círculo de Leitores, 2013).

Caridi, Giuseppe, Carlos III: un grande rey reformador en Nápoles y España (Madrid: La Esfera de los Libros, 2015).

Domínguez Ortiz, Antonio, Carlos III y la España de la Ilustración 2. ${ }^{2}$ ed.(Madrid: Alianza Editorial, 2016).

Ferreira, Nuno Alexandre Martins, A Institucionalização do Ensino da Náutica em Portugal (1779-1807) (Tese de doutoramento, Faculdade de Letras da Universidade de Lisboa, 2013).

História Geral da Civilização Brasileira, dir. Sérgio Buarque de Holanda e Pedro Moacyr de Campos, 2 (O Brasil Monárquico), 9. ${ }^{a}$ ed. (Rio de Janeiro: Bertrand Brasil, 2003).

Luís, Nuno de Castro, Afirmação europeia de uma monarquia transatlântica: estratégias políticodiplomáticas nos casamentos dos filhos de D. João VI (Tese de mestrado, Faculdade de Letras da Universidade de Lisboa, 2015).

Malerba, Jurandir, A Corte no Exilio. Civilização e Poder no Brasil às Vésperas da Independência (1808-1821) (São Paulo: Companhia das Letras, 2000).

Marques, João Francisco, “O Clero Nortenho e as Invasões Francesas" em Obra Selecta 1 (Lisboa: Roma Editora, 2008), 67-144.

Marques, João Francisco, "Oratória Sacra ou Parenética", em Dicionário de História Religiosa de Portugal, 4, dir. Carlos Moreira de Azevedo (Lisboa: Universidade Católica Portuguesa, Centro de Estudos de História Religiosa, 2001), 470-510.

Pedreira, Jorge, Costa, Fernando Dores, D. João VI, o Clemente, (Lisboa: Círculo de Leitores, 2006).

Pereira, Ângelo, As Senhoras Infantas filhas d'El-Rei D. João VI, fac-símile da edição de 1938 (Lisboa: Ex-Libris, 2004).

Pereira, Ângelo, D. João VI Príncipe e Rei, 1 (Lisboa: Empresa Nacional de Publicidade, 1953). 
Pereira, Sara Marques, D. Carlota Joaquina e os 'Espelhos de Clio': actuação política e figurações historiográficas (Lisboa; Livros Horizonte, 1999).

Petey-Girard, Bruno, "Parler des morts, parler de soi. Remarques sur la place du sujet dans les harangues funèbres", em De bonne vie s'ensuit bonne mort. Récits de mort, récits de vie en Europe $\left(X V^{e}-X V I I^{e}\right.$ siècle), dir. Patricia Eichel-Lojkine (Paris: Honoré Champion, 2006), 169-182.

Shami, Jeanne, "Women and Sermons", em The Oxford Handbook of the Early Modern Sermon, dir. Peter McCullought, Hugh Adlington e Emma Rhatigan (Oxford: Oxford University Press, 2011), 155-177.

Silva, Andrée Mansuy-Diniz, Portrait d'un homme d'État: D. Rodrigo de Sousa Coutinho, conte de Linhares (1755-1812), v. 2 (Paris: Centre Culturel Calouste Gulbenkian, 2006).

Silva, Carlos André Lopes da, A Real Companbia e Academia dos Guardas-Marinha: aspetos de uma instituição de ensino na alvorada da profissionalização do oficialato militar (18081839) (Tese de mestrado, Universidade Federal do Rio de Janeiro, 2012).

Tedim, José Manuel, “Aparatos Fúnebres, Ecos Saudosos nas Exéquias de D. Pedro II e D. João V", em Arte Efémera em Portugal (Lisboa: Fundação Calouste Gulbenkian, 2000), 237-279.

Tedim, José Manuel, "Carlo Fontana e as Exéquias de D. Pedro II na Igreja de Santo António dos Portugueses em Roma", I Congresso Internacional do Barroco: actas 2 (Porto: Reitoria da Universidade do Porto, Governo Civil do Porto, 1991), 503-518.

Tedim, José Manuel, "Festas Barrocas no Brasil Colonial. Exéquias de D. João V em S. Salvador da Baía e S. João d'El-Rei" em Relaciones artísticas entre la Península Ibérica y América. Actas del V Simposio Hispano-Portugués de Historia del Arte (Valladolid: s.n., 1990), 273-276.

Tedim, José Manuel, “Teatro da Morte e da Glória. Representações Fúnebres nas Exéquias de D. João V na Sé de Braga", Revista de Ciências Históricas 4, (1989): 281-292.

Ventura, António, Carlota Joaquina (1775-1830) (Lisboa: Círculo de Leitores, 2011).

Recibido: 26 de marzo de 2019

Aprobado: 31 de octubre de 2019 